\title{
Combination Treatment of Triamcinolone Acetonide and Ablative Fractional Laser for Hypertrophic Scars
}

\author{
Jeoung Hyun Nam \\ Eun Soo Park \\ Seung Min Nam \\ Ba Leun Han
}

Department of Plastic and Reconstructive Surgery, College of Medicine, Soonchunhyang University, Bucheon, Korea
Received December 1, 2018

Accepted December 18, 2018

\author{
Correspondence \\ Eun Soo Park \\ Department of Plastic and Reconstructive \\ Surgery, College of Medicine, Soonchunhyang \\ University, 170 Jomaro-ro, Wonmi-gu, Bucheon \\ 14584, Korea \\ Tel.: +82-32-621-5319 \\ Fax: +82-32-621-5016 \\ E-mail: peunsoolaschmc.ac.kr \\ (C) Korean Society for Laser Medicine and Surgery \\ (c) This is an open access article distributed under the \\ terms of the Creative Commons Attribution Non- \\ Commercial License (http://creativecommons.org/ \\ licenses/by-nc/4.0) which permits unrestricted non- \\ commercial use, distribution, and reproduction in any \\ medium, provided the original work is properly cited.
}

Hypertrophic scars are defined as visible and elevated scars that do not spread into the surrounding tissues and often regress spontaneously. They can be itchy, painful, and erythematous, so it is a challenging problem for doctors to manage them. This is because hypertrophic scars are caused by the proliferation of dermal tissue and the excessive accumulation of collagen, long-lasting inflammation, and fibrosis. Triamcinolone acetonide was used because it reduces the collagen and inflammatory process. A fractional laser was also used to flatten the overgrown tissues. Four patients who were treated with triamcinolone acetonide and fractional laser to treat a hypertrophic scar were included retrospectively. All patients were injected with triamcinolone acetonide and fractional laser simultaneously. The results were evaluated every session using the Vancouver Scar scale (VSS) and all patients were asked to express a 4-point subjective scale of satisfaction. Measuring the wound with photographs, the VSS score showed improvement over time. The average VSS score of pretreatment and posttreatment was 12 and 4 , respectively. The average number of treatments was 12.75 , and the average interval of treatments was 5 . Using a patient satisfaction scale, the patients were satisfied (Poor: 0\%, Fair: 25\%, Good: 50\%, Excellent: $25 \%)$. No significant adverse effects and complications were encountered. The simultaneous treatment using triamcinolone acetonide and fractional laser can be an effective treatment modality for treating hypertrophic scars.

\section{Key words}

Hypertrophic scar; Triamcinolone acetonide; Fractional laser 


\section{INTRODUCTION}

Hypertrophic scars are firm, raised within the site of injury, occasionally symptomatic, and usually develops within 4 to 8 weeks of injury. These scars are characterized by proliferation of the dermal tissue, with excessive deposition of fibroblast-derived extracellular matrix proteins and especially collagen, over long periods and by persistent inflammation and fibrosis. ${ }^{2}$

Numerous methods have been introduced for hypertrophic scars, but to date, none have been established as the optimal treatment. Among various methods, corticosteroids are usually used to control inflammation and reduce the bulk of hypertrophic scars. ${ }^{3}$ Triamcinolone acetonide, which is the most common corticosteroid used for the treatment of scars, have been shown to cause hypertrophic scar regression in vivo, mainly by decreasing collagen and glycosaminoglycan synthesis, by reducing the inflammatory process in the wound, by decreasing fibroblast proliferation and by increasing hypoxia. ${ }^{2}$

Recent advances in laser technology and applications, there is increasing evidence that fractional lasers are an emerging therapeutic option for the aesthetic restoration and functional enhancement of traumatic scars at virtually any location on the body. ${ }^{4}$ Fractional ablative lasers create zones of ablation at variable depths of the skin with the subsequent induction of a wound healing and collagen remodeling response. ${ }^{4}$ Laser treatment results in deep destructions, leading to cascade induction of heat shock proteins, and subsequently, acceleratedhealing process, delayed collagen synthesis, and regeneration. Also, lasers result in better penetration of drugs and other medications. ${ }^{3}$

In recent years, the combined treatment of conventional methods shows good results. For example, Manuskiatti and Fitzpatrick found clinical improvement of hypertrophic scars after treatment with an intralesional injection of triamcinolone acetonide combined with ContractubexH gel, which appears to be superior to intralesional triamcinolone administered alone in the treatment with no significant side effects. ${ }^{2}$ Khan et al. ${ }^{5}$ demonstrate that combined treatment of intralesional traimcinolone with 5-fluorouracil is more effective and gives rapid response with fewer side effects.

Although combination therapy may result in synergistic effects, the studies on this issue are not enough. In this study we wound like to introduce about usefulness of combination treatment of triamcinolone acetonide and ablative fractional laser for hypertrophic scar.

\section{CASE REPORT}

\section{Patients}

The 4 patients who were visiting our plastic and reconstructive surgery department during 2013-2018 were enrolled in the study, and patients developed hypertrophic scars due to trauma, burn and surgical procedure. Patients who had previously received other treatments for hypertrophic scar, who had less than 1 year of hypertrophic scar formation or who are currently taking steroid drugs are excluded.

\section{Study design}

Each patient received combined treatment of intralesional triamcinolone acetonide and fractional laser for hypertrophic scar. To minimize pain, topical anesthetic cream leutectic mixture of lidocaine and prilocaine; EMLA $^{\circledR}$ cream 5\%, Astra Zeneca, Sweden) was applied under an occlusive dressing for at least 1 hour. The injection was conducted using 27 gauge needle intradermally and concentration of triamcinolone acetonide $110-40 \mathrm{mg} /$ $\mathrm{ml}$ ) was determined by the location and thickness of the scar. Consecutively, Fractional $\mathrm{CO}_{2}$ laser (LineXel ${ }^{\circledR}$; UTI Co. Ltd, Seoul, Koreal, the pulse duration of $260-400 \mathrm{~ms}$, with a distance between spots of $0.85-0.9 \mathrm{~mm}$, and spot size of $1 \mathrm{~mm}$ was conducted. Settings were customerized for each patient at each treatment session according to scar thickness.

Table 1. Patient's characteristics and results

\begin{tabular}{|c|c|c|c|c|c|c|c|}
\hline No & Sex/Age & Location & Number of treatment & Interval of treatment & Satisfaction scale & Pre VSS scrore & Post VSS score \\
\hline 1 & $\mathrm{~F} / 10$ & Rt. Lower leg & 9 & 4 weeks & 3 & 10 & 4 \\
\hline 2 & $\mathrm{~F} / 41$ & Abdomen & 15 & 4 weeks & 4 & 13 & 4 \\
\hline 3 & $F / 31$ & Rt. Upper arm & 16 & 4 weeks & 4 & 13 & 3 \\
\hline 4 & $\mathrm{~F} / 51$ & Lt. forearm & 11 & 4 weeks & 3 & 12 & 5 \\
\hline Mean & 33.25 & & 12.75 & 4 weeks & 3.5 & 12 & 4 \\
\hline
\end{tabular}

VSS, Vancouver Scar scale. 


\section{Clinical assessment}

Clinical photographs were taken to evaluate patient satisfaction and objective improvement in every session. Photographs (Nikon D90; Nikon Corp., Tokyo, Japan) were taken under identical settings at baseline evaluation, every treatment visit (before and after session) and 1 month after the last session.

Results were evaluated every session using Vancouver Scar scale by experienced independent physician and all patients were asked to express a 4-point subjective scale of satisfaction (Poor: 1, Fair: 2, Good: 3, Exellent: 4).

All of the participants were women and mean age was 33.25 (range from 10 to 51). The average number of treatments was 12.75, and the average interval of treatments was 4 weeks. Most patients were satisfied with their appearance after the final session (Table 1).

Measuring the wound with photographs, Vancouver Scar scale shows improvement over time. The average score of pretreatment was 12, but in 1 month after the
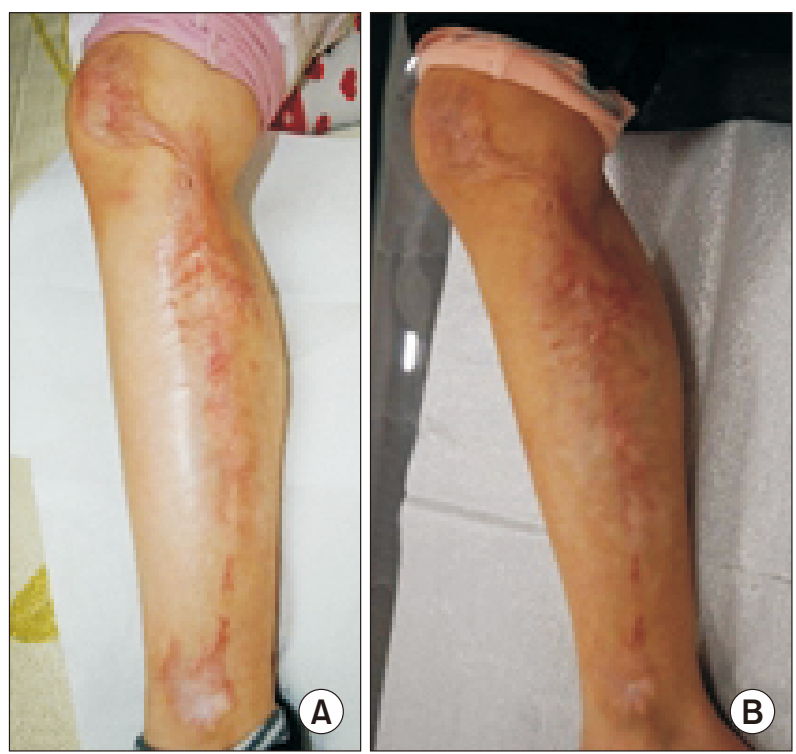

Fig. 1. Photographs of a 10-year-old female prior to treatment (A). After 16 session of treatment (B). last session, the score was decreased to 4 (Fig. 1, 2). Particularly, in pliability and scar height section, a decrease in score was observed evidently (Table 2).

There are no significant side effects and complication. The most frequent side effect was transient erythema. It occured in 2 of 4 patients, lasted for 2-3 days and all patients completely healed within 3 days spontaneously.

\section{DISCUSSION}

Hypertrophic scars are annoying and reduce the quality of life of patients in many ways. Although wide variety of treatments have been advocated for hypertrophic scar, such as pressure therapy, intralesional interferon, topical and intralesional corticosteroids, intralesional bleomycin, laser therapy, silicone gel sheetin, onion extract gel, and other therapies directed at collagen synthesis, treatment of hypertrophic scars can be complex and often requires a multimodal approach to therapy. ${ }^{2}$ We evaluated the state of vascularity, pigmentation, piliability and height The improvement was made in pliability and height more than in vascularity and pigmentation. Fractional ablative
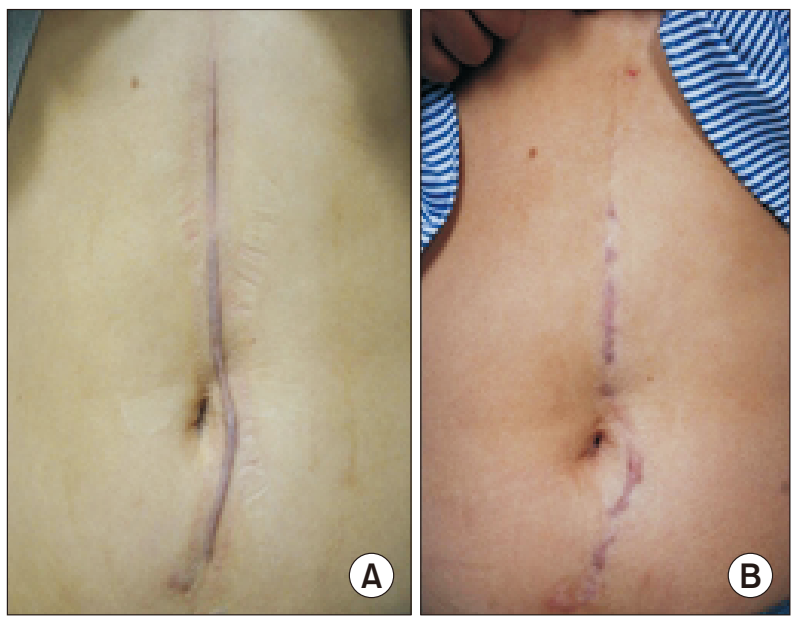

Fig. 2. Photographs of a 41-year-old female prior to treatment (A). After 15 session of treatment (B).

Table 2. Patient's Vancouver Scar scale

\begin{tabular}{|c|c|c|c|c|c|c|c|c|c|c|}
\hline & \multicolumn{2}{|c|}{ Vascularity } & \multicolumn{2}{|c|}{ Pigmentation } & \multicolumn{2}{|c|}{ Pliability } & \multicolumn{2}{|c|}{ Height } & \multicolumn{2}{|c|}{ Total } \\
\hline & Pre & Post & Pre & Post & Pre & Post & Pre & Post & Pre & Post \\
\hline 1 & 2 & 1 & 2 & 1 & 3 & 1 & 3 & 0 & 10 & 4 \\
\hline 2 & 3 & 0 & 3 & 2 & 4 & 1 & 3 & 1 & 13 & 4 \\
\hline 3 & 3 & 1 & 3 & 1 & 4 & 1 & 3 & 0 & 13 & 3 \\
\hline 4 & 2 & 1 & 2 & 2 & 5 & 2 & 3 & 0 & 12 & 5 \\
\hline Mean & 2.5 & 0.75 & 2.5 & 1.5 & 4 & 1.25 & 3 & 0.25 & 12 & 4 \\
\hline
\end{tabular}


$\mathrm{CO}_{2}$ laser improves rhytides, dyschromia, and textural irregularities. In addition, it was recently reported that ablative fractional $\mathrm{CO}_{2}$ laser can resurface mature scars to correct abnormal texture, thickness, and stiffness. ${ }^{6}$ It has been reported that scars treated with triamcinolone acetonide (T) showed decreased levels of the proteinase inhibitors alpha macroglobulinandalpha 2-antitrypsin in the scar. This leads to decreased collagenase (matrix metalloproteinase 1/MMP1) degradation which controls excessive and abnormal collagen seen in hypertrophic scars. ${ }^{\text {? }}$

In this study, we tried to investigate the interaction between existing treatment, and verify its safety. The results of our series indicate that combination same-session therapy with laser and laser-assisted delivery of triamcinolone acetonide offers efficient, safe, and effective treatment of challenging hypertrophic scars.

The limitation of our study is that the number of enrolled patients is small that diversity is not secured and could not evaluate the result accurately. Also, the lack of comparison with control group is another limitation. Despite of the effort to quantify scar assessments such as using the Vancouver scar scale, The evaluation itself was subjective and failed to provide an objective evaluation.

Among the many methods of hypertrophic scar, combination treatment of triamcinolone acetonide \& ablative fractional laser for hypertrophic scar can be useful meth- od. In the future, we shound carry out more generalized research by conducting research on more patients.

\section{REFERENCES}

1. Berman B, Maderal A, Raphael B. Keloids and hypertrophic scars: pathophysiology, classification, and treatment. Dermatol Surg 2017:43:S3-18.

2. Rabello FB, Souza CD, Farina Júnior JA. Update on hypertrophic scar treatment. Clinics (Sao Paulo) 2014;69:565-73.

3. Ogawa R. Keloid and hypertrophic scars are the result of chronic inflammation in the reticular dermis. Int J Mol Sci 2017; 18:606.

4. Waibel JS, Wulkan AJ, Shumaker PR. Treatment of hypertrophic scars using laser and laser assisted corticosteroid delivery. Lasers Surg Med 2013;45:135-40.

5. Khan MA, Bashir MM, Khan FA. Intralesional triamcinolone alone and in combination with 5-fluorouracil for the treatment of keloid and hypertrophic scars. J Pak Med Assoc 2014;64:1003-7.

6. Hultman CS, Edkins RE, Wu C, Calvert CT, Cairns BA. Prospective, before-after cohort study to assess the efficacy of laser therapy on hypertrophic burn scars. Ann Plast Surg 2013;70:521-6.

7. Rockwell WB, Cohen IK, Ehrlich HP. Keloid and hypertrophic scars: a comprehensive review. Plast Reconstr Surg 1989;84:827-37. 